\title{
Tecnura
}

\section{Reconocimiento y evaluación de posibles geositios asociados a dolinas en el departamento de Malargüe Provincia de Mendoza, Argentina}

\section{Recognition and Evaluation of Possibles Geosites Associated to Dolinas in Malargüe Department Mendoza Province, Argentina}

\author{
Valeria Sofía Cortez Taillant (iD) ${ }^{1}$, Agustín Arroqui Langer (iD)2
}

Fecha de Recepción: 26 de Mayo de 2020

Fecha de Aceptación: 24 de Febrero de 2021

Cómo citar: Cortez-Taillant., V.S. y Arroqui-Langer., A. (2021). Reconocimiento y evaluación de posibles geositios asociados a dolinas en el departamento de Malargüe Provincia de Mendoza. Tecnura, 25(68), 84-104. https://doi.org/10.14483/22487638.17134

\section{Resumen}

Objetivo: Evaluar y valorar sitios de interés geológico mediante el planteamiento de georrutas turísticas asociadas a geoformas kársticas (dolinas) para luego proponerlas en el proyecto Global Geosites de la Unión Internacional de Ciencias Geológicas (IUGS, por su sigla en inglés). Recomendar futuros estudios en la temática exokárstica, ya que la información es muy escasa, lo cual contribuiría a un mejor desarrollo turístico del departamento de Malargüe.

Metodología: La metodología aquí aplicada se abordó a partir del estudio de las geoformas kársticas mediante un exhaustivo trabajo de interpretación de imágenes satelitales y posterior control de campaña. Además, se desarrolló una valoración sobre la base de trabajos previos (Panizza y Piacente, 1993, Reynard, Fontana, Kozlik y Scapozza, 2007, Zouros, 2007, Coratza et al., 2012) y se basó en tres conjuntos de valores: valor científico, valor adicional y valor de uso.

Resultados: La dolina N. ${ }^{\circ} 6$ (laguna de La Niña Encantada) fue la que obtuvo mayor puntuación total, siendo casi perfecta; con valoraciones máximas en casi todos los criterios.

Conclusiones: Los datos obtenidos a partir de la valoración sugiere que la primer georruta propuesta, ubicada al norte del área de estudio, comprendida por las dolinas $\mathrm{N} .{ }^{\circ} 1$ a N. ${ }^{\circ}$, es la más propicia para la determinación de geositios. La valoración más alta de esta georruta fue de 9 puntos, laguna de La Niña Encantada, un registro casi perfecto en todos los criterios de clasificación.

Financiamiento: Departamento de Geología, Universidad Nacional de San Juan.

Palabras clave: cañón kárstico, dolinas, geositios, yeso.

\footnotetext{
${ }^{1}$ Licenciada en Ciencias Geológicas, perteneciente a Consejo Nacional de Investigaciones Científicas y Técnicas-Centro de Investigaciones de la Geósfera y Biósfera (Conicet-Cigeobio) e Instituto de Geología “Dr. Emiliano P. Aparicio" Ingeo. Gabinete de Geología Ambiental. Departamento de Geología. Facultad de Ciencias Exactas, Físicas y Naturales FCEFyN. Universidad Nacional de San Juan, Argentina. Contacto: valeriasofia1292@gmail.com

${ }^{2}$ Doctor en Ciencias Geológicas, licenciado en Ciencias Geológicas. Docente e investigador del Instituto de Investigaciones Mineras y Departamento de Ingeniería en Minas pertenecientes a Facultad de Ingeniería de la Universidad Nacional de San Juan. San Juan, Argentina. Contacto: aarroqui@unsj.edu.ar
} 
Reconocimiento y evaluación de posibles geositios asociados a dolinas en el departamento de Malargüe Provincia de Mendoza

Cortez-Taillant., V.S. y Arroqui-Langer., A.

\begin{abstract}
Objective: Evaluate and assess sites of geological interest by proposing tourist georoutes associated with karst geoforms (sinkholes) and then propose them in the Global Geosites project of the International Union of Geological Sciences (IUGS). Recommend future studies on the exokarst theme since it is very scarce and this would contribute to a better tourist development in the Malargüe department.

Methodology: The methodology applied here was approached from the study of the karst geoforms through an exhaustive work of interpretation of satellite images and subsequentcampaign control. In addition, an assessment is developed based on previous work (Panizza y Piacente, 1993, Reynard, Fontana, Kozlik y Scapozza, 2007, Pereira, Pereira y Caetano-Alves, 2007, Zouros, 2007, Coratza et al., 2012) and is based on three sets of values: Scientific Value, Additional Value and Use Value.

Results: The sinkhole N ${ }^{\circ} 6$ (Laguna de la Niña Encantada) is the one that obtained the highest total score, being almost perfect; with maximum ratings on almost all criteria.

Conclusions: The data obtained from the assessment suggests that the first proposed georoute, located to the north of the study area, comprised of sinkholes 1 to 7 , is the most favorable for the determination of geosites. The highest evaluation of this georoute was 9 points, Laguna de la Niña Encantada, being almost perfect in all the classification criteria.

Financing: Department of Geology, National University of San Juan.
\end{abstract}

Keywords: canyon karst, geosites, gypsum, sinkhole.

\title{
Tabla de Contenidos
}

Página

$\begin{array}{ll}\text { INTRODUCCIÓN } & 86\end{array}$

$\begin{array}{lc}\text { METODOLOGÍA } & \mathbf{8 7}\end{array}$

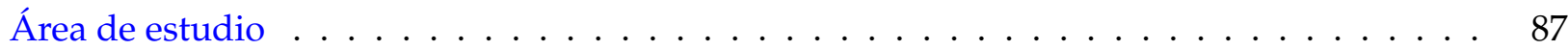

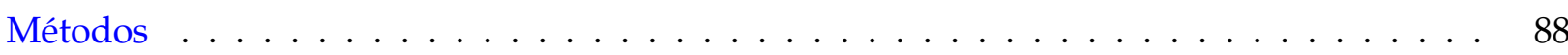

$\begin{array}{lr}\text { RESULTADOS } & \mathbf{8 9}\end{array}$

Reconocimiento general de georrutas propuestas con dolinas . . . . . . . . . . . . . . . . . . . . 89

Georruta N. ${ }^{\circ} 1$ : zona norte 42 kilómetros de longitud . . . . . . . . . . . . . . . . . . . . . . . . . . .

Georruta N. ${ }^{\circ}$ 2: zona sur 38 kilómetros de longitud . . . . . . . . . . . . . . . . . 92

Evaluación preliminar de geositios propuestos . . . . . . . . . . . . . . . . 92

Georruta N. ${ }^{\circ}$ : zona norte $($ tabla II $) \ldots \ldots \ldots \ldots$. . . . . . . . . . . . . . . . . . . . . . . . . .

Georruta N. ${ }^{\circ}$ 2: zona sur $($ tabla II $) \ldots \ldots \ldots \ldots$. . . . . . . . . . . . 99

$\begin{array}{ll}\text { CONCLUSIONES Y RECOMENDACIONES } & 101\end{array}$

$\begin{array}{ll}\text { FINANCIAMIENTO } & 102\end{array}$

$\begin{array}{lr}\text { REFERENCIAS } & 102\end{array}$ 


\section{INTRODUCCIÓN}

Las dolinas son depresiones cerradas, de forma circular o elipsoidal en planta, de metros a un kilómetro de diámetro, y su profundidad puede ser de pocos metros a más de un centenar. Pueden presentarse aisladas, formando uvalas (producto de la unión de dos o más dolinas) o agrupadas formando campos de dolinas. Otras geoformas particulares vinculadas con dolinas son los canyons karst, o cañones kársticos. Se generan por la coalescencia de varias dolinas conectadas ya sea en profundidad o en superficie por el mismo drenaje. Esta geoforma evoluciona con la pérdida paulatina de la forma circular que caracteriza a las dolinas tendiente a la morfología clásica de un curso fluvial. Por lo general, las dolinas no presentan una sola génesis por lo que se las denomina poligenéticas. Los procesos que generan dolinas son la disolución, flexión, sofusión y colapso (Cramer, 1941).

Las dolinas siempre han sido consideradas geoformas llamativas y distintivas por diversas culturas del mundo. Normalmente, los términos específicos o locales para nombrar estas geoformas kársticas son sumidero y dolina. En áreas donde las dolinas son abundantes y/o de tamaños considerables, los habitantes suelen crear historias o leyendas sobre su aparición o formación. Su valor mitológico o místico, su importante historia en un sentido amplio y su valor escénico han favorecido a la designación como áreas protegidas (p. ej., (Lewis, 2008, Kiernan, 2010, Fassoulas, Mouriki, Dimitriou-Nikolakis y Iliopoulos, 2012). El área protegida más importante del mundo que está vinculada con dolinas es el Bottomless Lakes State Park, de Nuevo México (Estados Unidos). Este parque incluye un área con dolinas formando lagos, generadas en un entorno hidrogeológico particular (Coratza et al., 2012).

La protección de estas áreas está basada en el valor ecológico; las geoformas kársticas y su hidroquímica son esenciales en el ecosistema de estos lugares. Otro de los ejemplos es el área del León, en Florida (Estados Unidos), un parque regional centrado en dolinas, donde el paisaje regional tiene centenares de lagos circulares (dolinas) en la toda la península de Florida. Lagunas de Cañada del Hoyo es un parque regional en España dedicado exclusivamente a dolinas. En Croacia, una de las dolinas más grandes tiene $520 \mathrm{~m}$ de profundidad llamado Modro Jezero (Lago Rojo) que se ha convertido en una importante atracción turística. También los cenotes, que son dolinas de colapso con agua en su interior en la península de Yucatán (México), son intensamente visitados por turistas. En la región del Caribe, las dolinas llamadas agujeros azules (blue holes) se han convertido en lugares fantásticos para las prácticas de buceo y sus imágenes aéreas son conocidas en todo el mundo (Coratza et al., 2012).

El objetivo de este trabajo es evaluar y valorar sitios de interés geológico a partir del trabajo realizado por Cortez Taillant (2017) planteando georrutas turísticas (Palacio-Prieto, De Castro-Martínez y González, 2019) asociadas a geoformas kársticas (dolinas) en el departamento de Malargüe, en la Provincia de Mendoza (Argentina) con el fin de proponerlas como posibles geositios en el proyecto Global Geosites de la Unión Internacional de Ciencias Geológicas (IUGS, por su sigla en inglés). Así 
mismo, se pretende promover futuros estudios en la temática exokárstica -ya que la información es muy escasa en esta región- y ello contribuiría a un mejor desarrollo turístico en el área de interés.

\section{METODOLOGÍA}

\section{Área de estudio}

El área de estudio se encuentra en el sector noroeste del departamento de Malargüe en los distritos Río Grande y ciudad de Malargüe, suroeste de la Provincia de Mendoza, República Argentina (figura 1).

Se accede desde San Rafael hacia el suroeste por Ruta Nacional N. ${ }^{\circ} 144$, hasta el empalme con Ruta Nacional N. ${ }^{\circ}$ 40. Luego se debe tomar hacia el sur hasta llegar a Ruta Provincial N. ${ }^{\circ} 222$. A través de esta vía, en dirección oeste, se accede al sector centro-norte del área de estudio; pasando por el paraje de Los Molles, el valle de Las Leñas y Valle Hermoso. El sector sur del área se puede recorrer partiendo desde la ciudad de Malargüe, hacia el oeste y transitando por el camino que conduce al atractivo turístico de los Castillos de Pincheira.

Las particularidades geológicas y climáticas de la región de Malargüe, han dado como resulta-
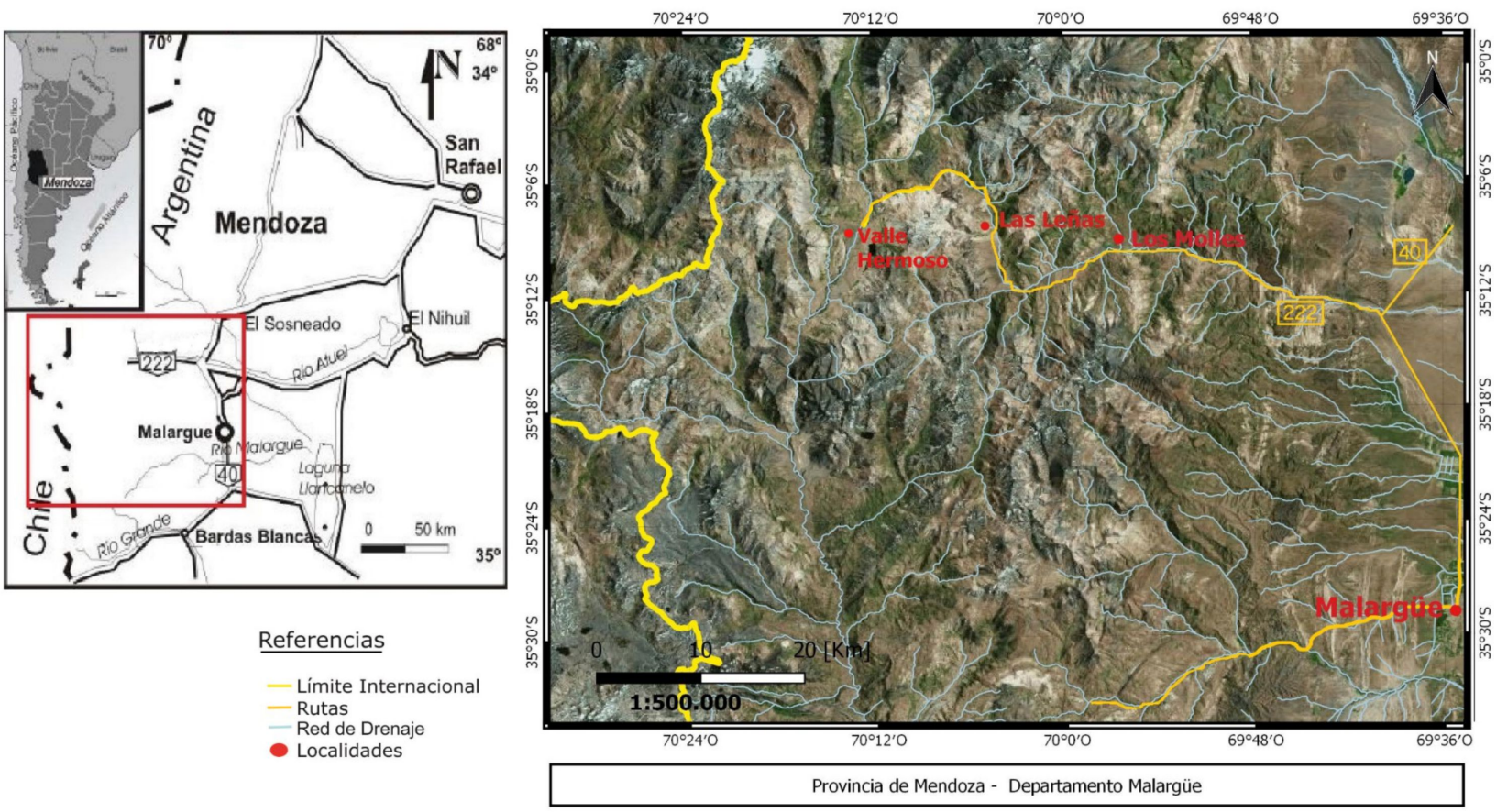

Figura 1. Mapa de ubicación del área de trabajo

Fuente: elaboración propia. 
do un paisaje exokárstico sobre el yeso sedimentario de la formación Auquilco, de edad Jurásica superior-Cretácica; así como la acción hídrica a niveles superficial ysubterráneo, ya que las rocas intervinientes tienen un alto potencial de disolución. Estos factores han generado en grandes cantidades de dolinas.

\section{Métodos}

Metodológicamente se abordó el estudio de las geoformas kársticas mediante un exhaustivo trabajo de interpretación de imágenes satelitales (con la identificación de 1999 geoformas) y posterior control de campaña. Se propone en este trabajo destacar y valorizar solo 15 dolinas que, por sus características relevantes, incitan ser propuestas como geositios.

Numerosos métodos, tanto cualitativos como cuantitativos, para evaluar a dolinas como geositios están disponibles en la literatura científica. La metodología aquí aplicada se desarrolla sobre la base de trabajos previos (Panizza y Piacente, 1993, Reynard, Fontana, Kozlik y Scapozza, 2007, Pereira, Pereira y Caetano-Alves, 2007,Zouros, 2007, Coratza et al., 2012) y en tres conjuntos de valores (valor científico, valor adicional y valor de uso). Así mismo, cada valor posee distintos criterios de evaluación (tabla I).

Tabla I. Simbología aplicada a la clasificación de geositios

\begin{tabular}{|c|c|c|c|c|}
\hline Valor & Criterios & & Símbolo & Puntuación \\
\hline \multirow{4}{*}{ Científico } & Modelo paleogeomorfológico & & $\mathrm{MP}$ & $0-1$ \\
\hline & Rareza o unicidad & & $\mathrm{R}-\mathrm{U}$ & $0-1$ \\
\hline & Representatividad & & $\mathrm{R}$ & $0-1$ \\
\hline & Integridad & & I & $0-1$ \\
\hline \multirow{7}{*}{ Adicionales } & Ecológico & Ecología & Ec & $0-1$ \\
\hline & Estético & & Es & - \\
\hline & & Diversidad de color & $\mathrm{D}$ & $0-1$ \\
\hline & & Naturalidad del sitio & $\mathrm{N}$ & $0-1$ \\
\hline & Cultural & & $\mathrm{C}$ & - \\
\hline & & Importancia religiosa & IR & $0-1$ \\
\hline & & Importancia histórica & $\mathrm{IH}$ & $0-1$ \\
\hline Uso & $\begin{array}{l}\text { Accesibilidad, visibilidad, } \\
\text { servicios e importancia } \\
\text { para la educación. }\end{array}$ & & $\mathrm{U}$ & $0-1$ \\
\hline
\end{tabular}

Fuente: modificado de (Coratza et al., 2012). 
El valor científico está basado en cuatro criterios que son sugeridos por (Reynard, Fontana, Kozlik y Scapozza, 2007): a) modelo paleogeomorfológico, que se refiere a la importancia del sitio para el clima de la Tierra en la historia; b) rareza/unicidad, que alude a su particularidad con respecto a un espacio de referencia; c) representatividad, que trata sobre su ejemplaridad con respecto a un espacio de referencia; y finalmente d) integridad, que concierne a su estado de conservación que depende de factores naturales y antropogénicos.

Los valores adicionales toman en cuenta los aspectos ecológicos, estéticos y culturales (Panizza y Piacente, 1993). Este parámetro pone de relieve los posibles vínculos entre las características geomorfológicas y otros aspectos naturales y culturales.

- El valor ecológico toma la importancia del geomorfositio por sus implicancias ecológicas (exclusivamente si tienen una particular fauna o vegetación), con referencia a las normas de protección existentes por razones ecológicas.

- El valor estético tiene en cuenta la percepción de la belleza del paisaje y, en ese sentido, su evaluación es la más subjetiva (Regolini-Bissig, 2010). Por esta razón, con el fin de reducir la subjetividad involucrada -basada en (Reynard, Fontana, Kozlik y Scapozza, 2007,Pralong, 2005, Coratza et al., 2012)- se ha introducido una serie de parámetros objetivos en la evaluación. Estos consisten en: a) diversidad de color (p. ej., contraste debido a cambios litológicos); ii) naturalidad del sitio (p. ej., ambientes prístinos).

- El valor cultural incluye diferentes subcriterios (Panizza, 1996): a) importancia religiosa; b) importancia histórica en un sentido amplio incluyendo arqueología, prehistoria e historia.

El valor de uso de un sitio se define a partir de su accesibilidad, visibilidad, servicios (en cuanto a la presencia de equipos y servicios de apoyo en los alrededores) e importancia para la educación (escuela, universidades).

En el área de estudio solo se ponderaron las dolinas que forman parte de las dos georrutas propuestas. El valor total de una geoforma (dolina) puede resultar de la suma de las puntuaciones de todos los criterios, donde 10 es la puntuación más alta.

\section{RESULTADOS}

\section{Reconocimiento general de georrutas propuestas con dolinas}

En el área de estudio se proponen dos georrutas a partir de la cercanía de los puntos de interés: una en la zona norte y otra en la zona sur (figura 2). Ambas involucran una serie de dolinas y uvalas, donde se conjugan tanto geoformas kársticas conocidas como atractivos turísticos, así como otras desconocidas hasta el momento. A continuación, se muestran las georrutas con sus respectivos puntos de interés. 
Reconocimiento y evaluación de posibles geositios asociados a dolinas en el departamento de Malargüe Provincia de Mendoza

Cortez-Taillant., V.S. y Arroqui-Langer., A.

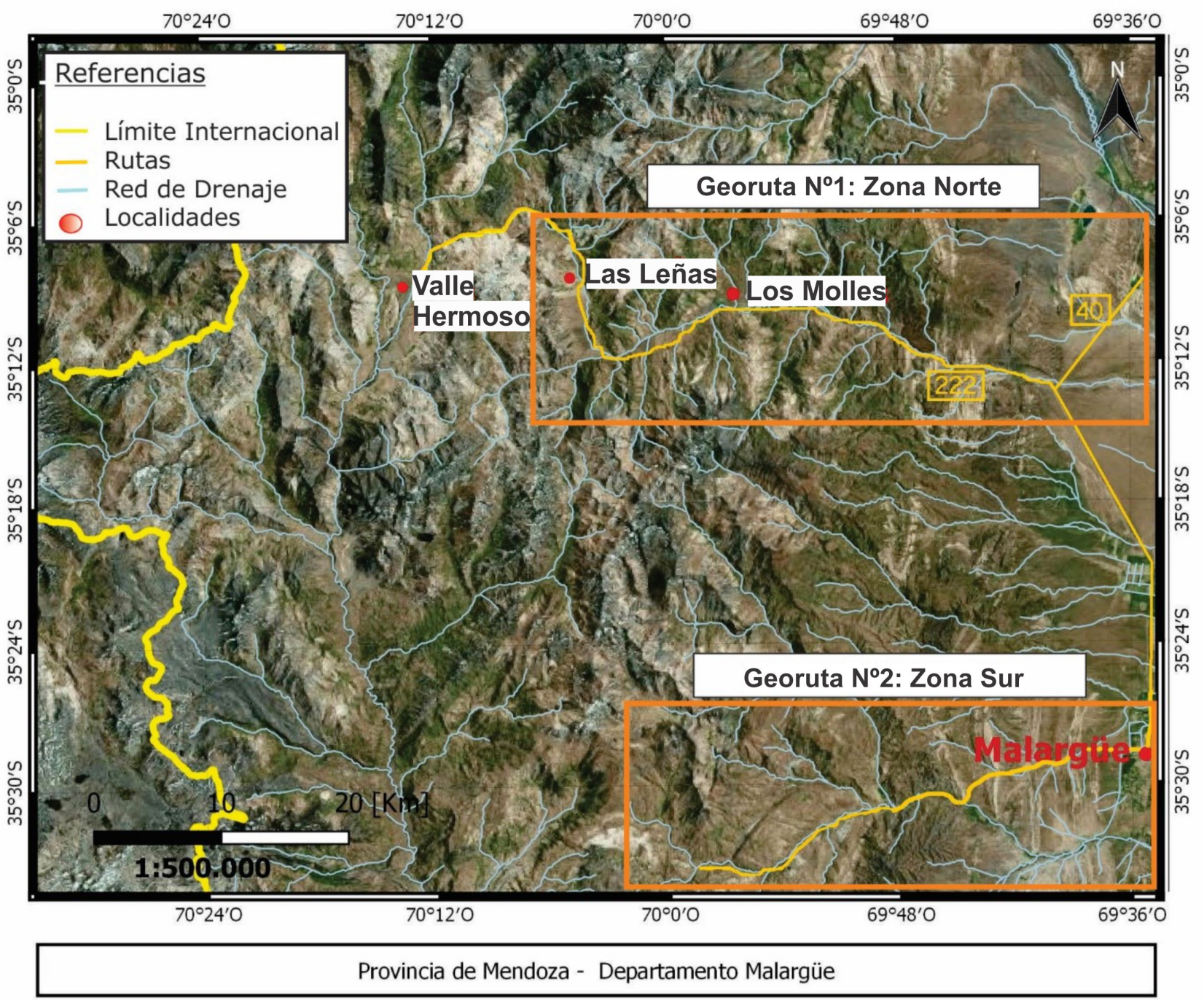

Figura 2. Mapa de ubicación del área de trabajo con las 2 georrutas propuestas enmarcadas en color naranja

Fuente: elaboración propia.

\section{Georruta N. ${ }^{\circ}$ : zona norte 42 kilómetros de longitud}

Se accede por Ruta Provincial 222 hacia el oeste y luego hacia el norte, camino al Complejo Las Leñas. Cada parada propuesta corresponde a un geositio: la primera pertenece a la dolina aislada N. 1 (canyon karst), ubicada sobre la misma Ruta 222, frente al valle de Las Leñas. La segunda es la más importante, ya que involucra al pozo de Las Ánimas, el cual ya es un sitio de interés geológico de Malargüe. Este corresponde al campo de dolinas N. ${ }^{\circ}$, dolinas N. ${ }^{\circ} 2$ y N.$^{\circ} 3$. La tercera, situada en la localidad de Los Molles, concierne al pozo de Las Animitas, que pertenece al campo N. ${ }^{\circ}$, dolinas $\mathrm{N}^{\circ} 4$ y N. ${ }^{\circ}$ 5. Y, por último, también en la localidad de Los Molles, se ubica el sitio de interés 
Reconocimiento y evaluación de posibles geositios asociados a dolinas en el departamento de Malargüe Provincia de Mendoza

Cortez-Taillant., V.S. y Arroqui-Langer., A.

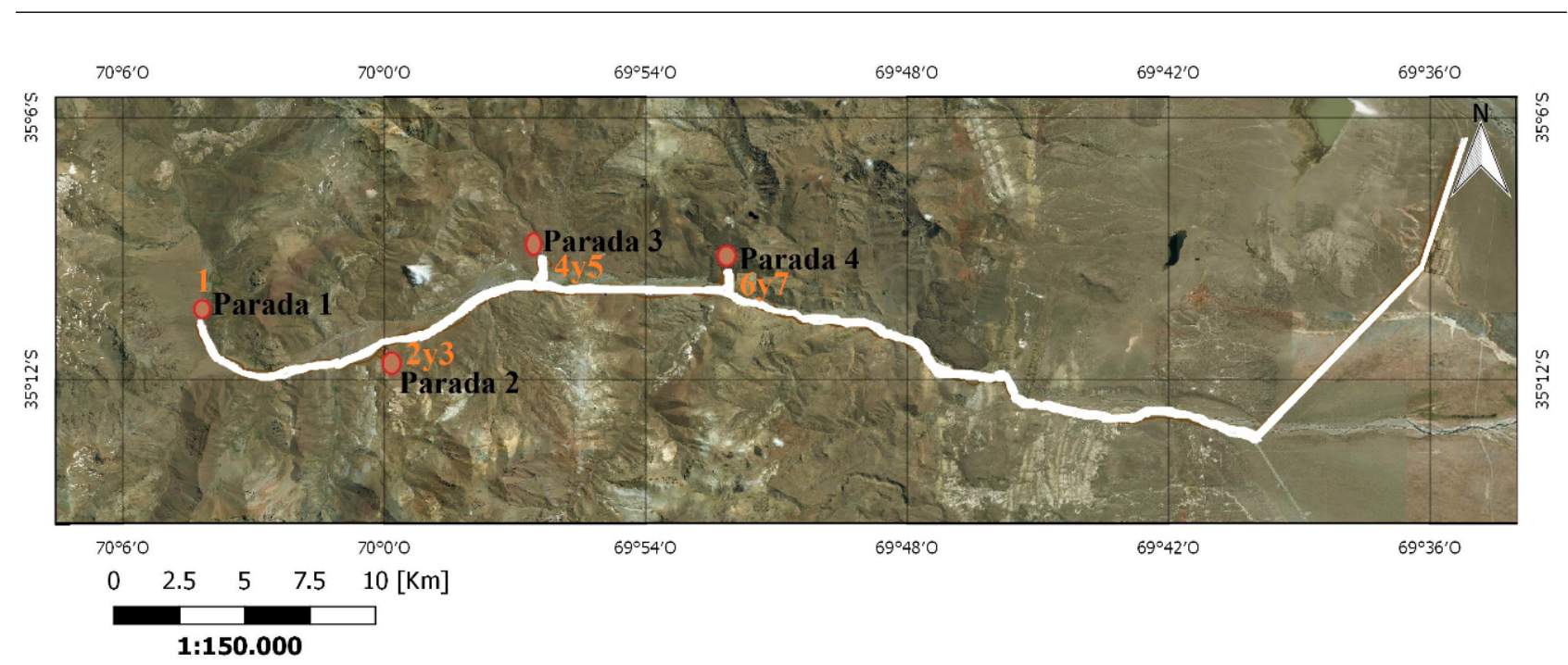

Figura 3. Georruta N. ${ }^{\circ} 1$ en zona norte, en blanco demarcada la Ruta 222 con paradas (geositios) y dolinas enumeradas de 1 a 7 .

Fuente: imagen satelital Bing, mapa elaboración propia.

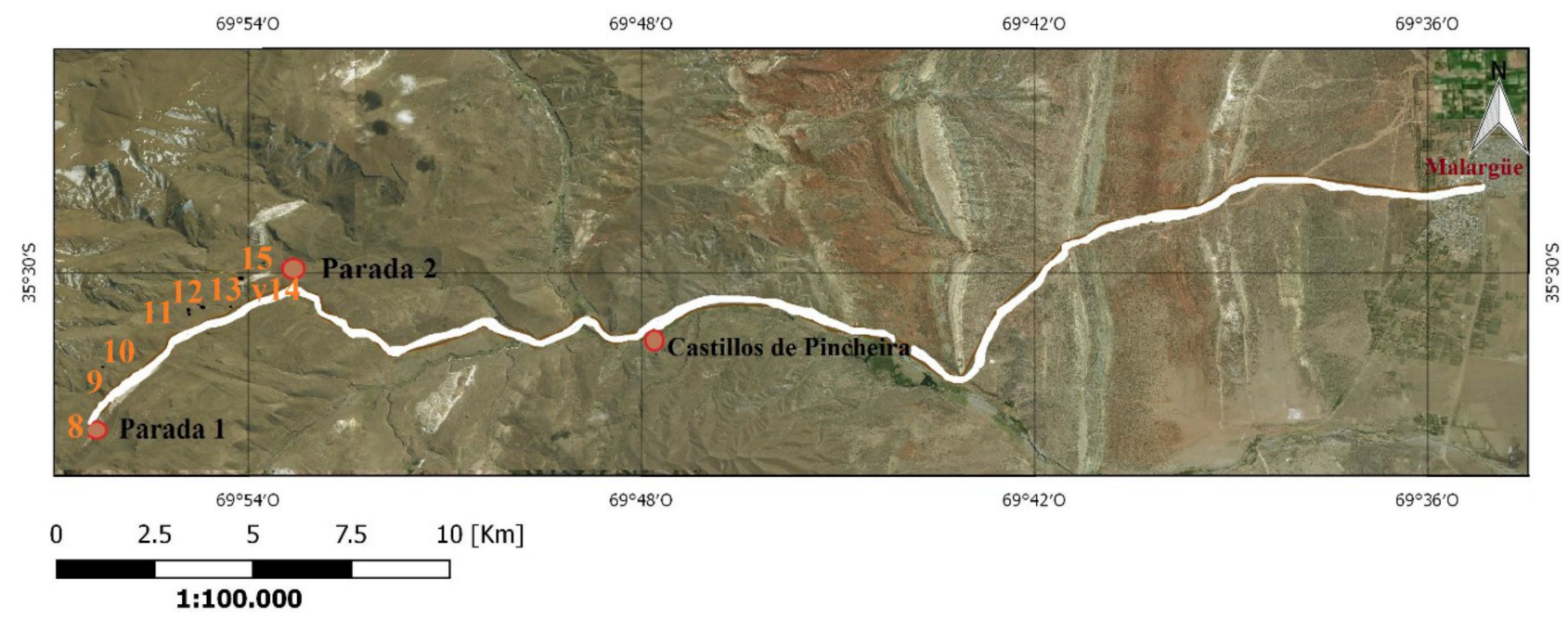

Figura 4. Georruta N. ${ }^{\circ} 2$ en camino a Castillos de Pincheira en zona sur, con paradas (geositios) y dolinas enumeradas de 8 a 15.

Fuente: imagen satelital Bing, mapa elaboración propia.

más popular, que es la laguna de La Niña Encantada y Lagunita (propuesta en este trabajo). Ambas constituyen el campo N. ${ }^{\circ} 3$ y son las dolinas $\mathrm{N} .^{\circ} 6$ y N. ${ }^{\circ}$. En esta georruta además de las dolinas también se pueden apreciar atractivas coladas basálticas y basaltos columnares sobre las laderas de Los Molles, lo que convierte a esta georruta en un importante atractivo turístico (figura 3). 


\section{Georruta N. ${ }^{\circ}$ 2: zona sur 38 kilómetros de longitud}

Esta georuta se propone en la zona sur del área de estudio, se ubica en dirección oeste de la ciudad de Malargüe, por camino hacia Los Castillos de Pincheira. Este sitio de interés geológico (no kárstico) se trata de un área protegida de unas 650 ha, cuyas formaciones geológicas, conocidas como castillos, fueron declarados Monumentos Naturales por su gran belleza escénica y su valor geomorfológico. La unidad de conservación está comprendida dentro de la ecorregión patagónica (municipalidad de Malargüe-Turismo).

Desde la parada 1 hasta la 2, se podrán observar 8 dolinas aisladas, las cuales están enumeradas desde 8 a 15 respectivamente, y que corresponden a los geositios 5 a 11. Todas se ubican cerca del camino, algunas pueden apreciarse a simple vista desde un vehículo y a otras se accede caminando no más de 20 metros de distancia (figura 4).

\section{Evaluación preliminar de geositios propuestos}

Luego de haber aplicado la clasificación propuesta a las dolinas, se obtuvo la valoración total para cada una de estas. Se destaca que en los casos de valor cero (0) es por no poseer puntuación o por no haber datos de estas.

\section{Georruta $N .^{\circ}$ 1: zona norte (tabla II)}

De acuerdo con los geositios propuestos en esta georruta se valora a la dolina N. 1 (canyon karst) (figura 5, geositio 1) con 4,5; con valor máximo en rareza (por ser la única en su morfología) y representatividad. El valor de uso es bajo debido a que solo se considera el acceso y su importancia para la educación por ser un ejemplar excelente de este tipo en el área; además posee poca visibilidad y no brinda ningún tipo de servicio a los turistas (figuras 6a y 6b).

En el campo N. ${ }^{\circ} 1$ (pozo de Las Ánimas) (figura 7, geositio 2), ambas dolinas fueron valoradas en rareza con 0,5 por ser común su ubicación en el área respecto a las otras dolinas, pero por poseer tamaños significativamente distintos a las demás (>200 metros de diámetro aproximadamente) (figuras $8 \mathrm{a}$ y 8b). En los valores estéticos se determinaron con puntuación máxima por su inigualable apariencia; y en cuanto al valor de uso, también se les proporcionó puntuación máxima por poseer accesibilidad, información educativa y carteles alusivos al cuidado del medio ambiente.

En cuanto al valor cultural son de relevada importancia debido a que abarca las temáticas religión e historia de la zona. Los mapuches (pueblo originario del sur argentino-chileno), llamaban a este lugar "Trolope-Co", o "agua del gritadero de las ánimas", de aquí que por siglos su nombre es protagonista de varias leyendas que han transcurrido en la historia de los pobladores rurales de generación en generación (comunicación verbal con habitante de Los Molles).

En el campo N. ${ }^{\circ} 2$ (pozo de Las Animitas) (figura 9, geositio 3) los valores de ambas dolinas (N. ${ }^{\circ}$ 4 y N. ${ }^{\circ}$ ) son bajos; en el caso de la representatividad es 0,5 por no ser el mejor ejemplo de la zona de 
Reconocimiento y evaluación de posibles geositios asociados a dolinas en el departamento de Malargüe Provincia de Mendoza

Cortez-Taillant., V.S. y Arroqui-Langer., A.

acuerdo con su morfología; y el valor de uso también es bajo, debido a que solo se considera la huella cercana a su ubicación por la cual se puede acceder. Cabe destacar que, si bien este sitio de interés no presenta ningún tipo de servicio ni señalización, se ubica próximo al conocido Hostel Los Molles (figuras 10a y 10b).

Tabla II. Clasificación de geositios modificado de (Coratza et al., 2012), aplicado a la georruta N. ${ }^{\circ} 1$

\begin{tabular}{|c|c|c|c|c|c|c|c|c|c|c|c|c|c|}
\hline \multicolumn{3}{|c|}{ Georruta N. ${ }^{\circ} 1$} & \multicolumn{11}{|c|}{ Clasificación de geositios propuestos } \\
\hline \multirow{3}{*}{ Campo N..$^{\circ}$} & \multirow{3}{*}{ Dolina N..$^{\circ}$} & \multirow{3}{*}{ Dolina aislada $\mathrm{N} .^{\circ}$} & \multirow{2}{*}{\multicolumn{4}{|c|}{ Valor Científico }} & \multicolumn{5}{|c|}{ Valor adicional } & \multirow{3}{*}{$\begin{array}{c}\text { Valor de uso } \\
\text { U }\end{array}$} & \multirow{3}{*}{ Valoración total } \\
\hline & & & & & & & \multirow{2}{*}{$\begin{array}{l}\text { Ec } \\
\text { Ec }\end{array}$} & \multicolumn{2}{|c|}{ Es } & \multicolumn{2}{|c|}{$\mathrm{C}$} & & \\
\hline & & & MP & R-U & $\mathrm{R}$ & I & & $\mathrm{D}$ & $\mathrm{N}$ & IR & $\mathrm{IH}$ & & \\
\hline- & - & 1 (ck) & 0 & 1 & 1 & 1 & 0 & 0 & 1 & 0 & 0 & 0,5 & 4,5 \\
\hline \multirow{2}{*}{1} & 2 & - & 0 & 0,5 & 1 & 1 & 0 & 1 & 1 & 1 & 1 & 1 & 7,5 \\
\hline & 3 & - & 0 & 0,5 & 1 & 1 & 0 & 1 & 1 & 1 & 1 & 1 & 7,5 \\
\hline \multirow[t]{2}{*}{2} & 4 & - & 0 & 0 & 0,5 & 1 & 0 & 0 & 1 & 0 & 0 & 0,2 & 2,7 \\
\hline & 5 & - & 0 & 0 & 0,5 & 1 & 0 & 0 & 1 & 0 & 0 & 0,2 & 2,7 \\
\hline \multirow{2}{*}{ o } & 6 & - & 0 & 1 & 1 & 1 & 1 & 1 & 1 & 1 & 1 & 1 & 9 \\
\hline & 7 & - & 0 & 0 & 0 & 1 & 0 & 0,5 & 1 & 0 & 0 & 1 & 3,5 \\
\hline
\end{tabular}

Fuente: elaboración propia.

Tabla III. Clasificación de geositios modificado de (Coratza et al., 2012), aplicado a la georruta N. ${ }^{\circ 2}$

\begin{tabular}{|c|c|c|c|c|c|c|c|c|c|c|c|c|c|}
\hline \multicolumn{3}{|c|}{ Georruta N. ${ }^{\circ} 2$} & \multicolumn{11}{|c|}{ Clasificación de geositios propuestos } \\
\hline \multirow{3}{*}{ Campo N. ${ }^{\circ}$} & \multirow{3}{*}{ Dolina $N .^{\circ}$} & \multirow{3}{*}{ Dolina aislada $\mathrm{N}^{\circ}$} & \multirow{2}{*}{\multicolumn{4}{|c|}{ Valor científico }} & \multicolumn{5}{|c|}{ Valor adicional } & \multirow{3}{*}{$\begin{array}{c}\text { Valor de uso } \\
\text { U }\end{array}$} & \multirow{3}{*}{ Valoración total } \\
\hline & & & & & & & \multirow{2}{*}{$\begin{array}{c}\text { Ec } \\
\text { Eco }\end{array}$} & \multicolumn{2}{|c|}{ Es } & \multicolumn{2}{|c|}{$\mathrm{C}$} & & \\
\hline & & & MP & $\mathrm{R}-\mathrm{U}$ & $\mathrm{R}$ & I & & $\mathrm{D}$ & $\mathrm{N}$ & IR & $\mathrm{IH}$ & & \\
\hline- & - & 8 & 0 & 0,5 & 0 & 1 & 0 & 0,5 & 1 & 0 & 0 & 0,2 & 3,2 \\
\hline- & - & 9 & 0 & 0 & 0 & 1 & 0 & 0 & 1 & 0 & 0 & 0,2 & 2,2 \\
\hline- & - & 10 & 0 & 0 & 0 & 1 & 0 & 0 & 1 & 0 & 0 & 0,2 & 2,2 \\
\hline- & - & 11 & 0 & 0 & 0 & 1 & 0 & 0 & 1 & 0 & 0 & 0,2 & 2,2 \\
\hline- & - & 12 & 0 & 0 & 0 & 1 & 0 & 0 & 1 & 0 & 0 & 0,2 & 2,2 \\
\hline- & - & 13 & 0 & 0 & 0 & 1 & 0 & 0 & 1 & 0 & 0 & 0,2 & 2,2 \\
\hline- & - & 14 & 0 & 0,5 & 0 & 1 & 0 & 0,5 & 1 & 0 & 0 & 0,2 & 3,2 \\
\hline - & - & 15 & 0 & 0,5 & 0 & 1 & 0 & 0,5 & 1 & 0 & 0 & 0,2 & 3,2 \\
\hline
\end{tabular}

Fuente: elaboración propia. 
Reconocimiento y evaluación de posibles geositios asociados a dolinas en el departamento de Malargüe Provincia de Mendoza

Cortez-Taillant., V.S. y Arroqui-Langer., A.

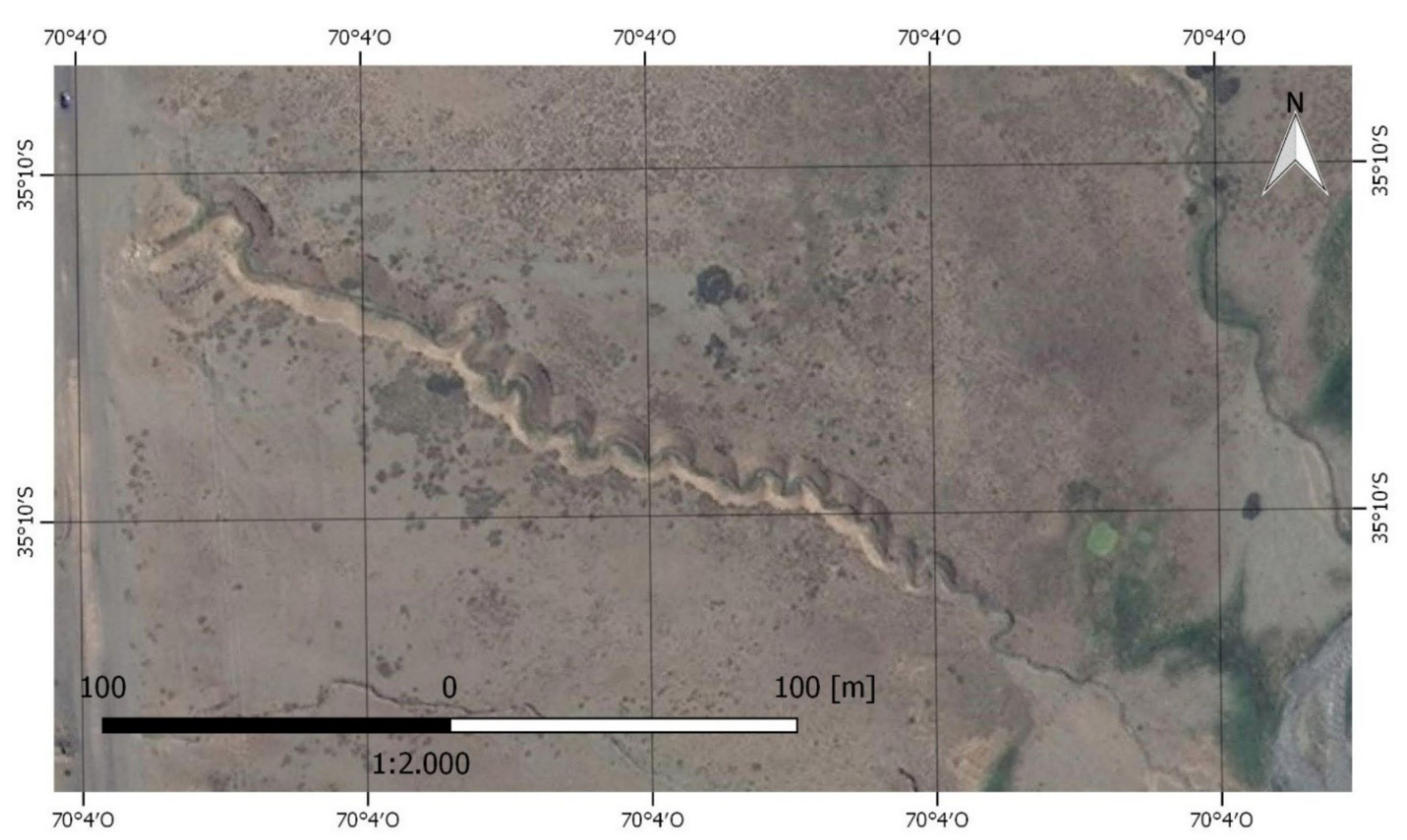

Figura 5. Canyon karst, al oeste Ruta Provincial 222. Geositio 1

Fuente: imagen satelital Bing, mapa elaboración propia.

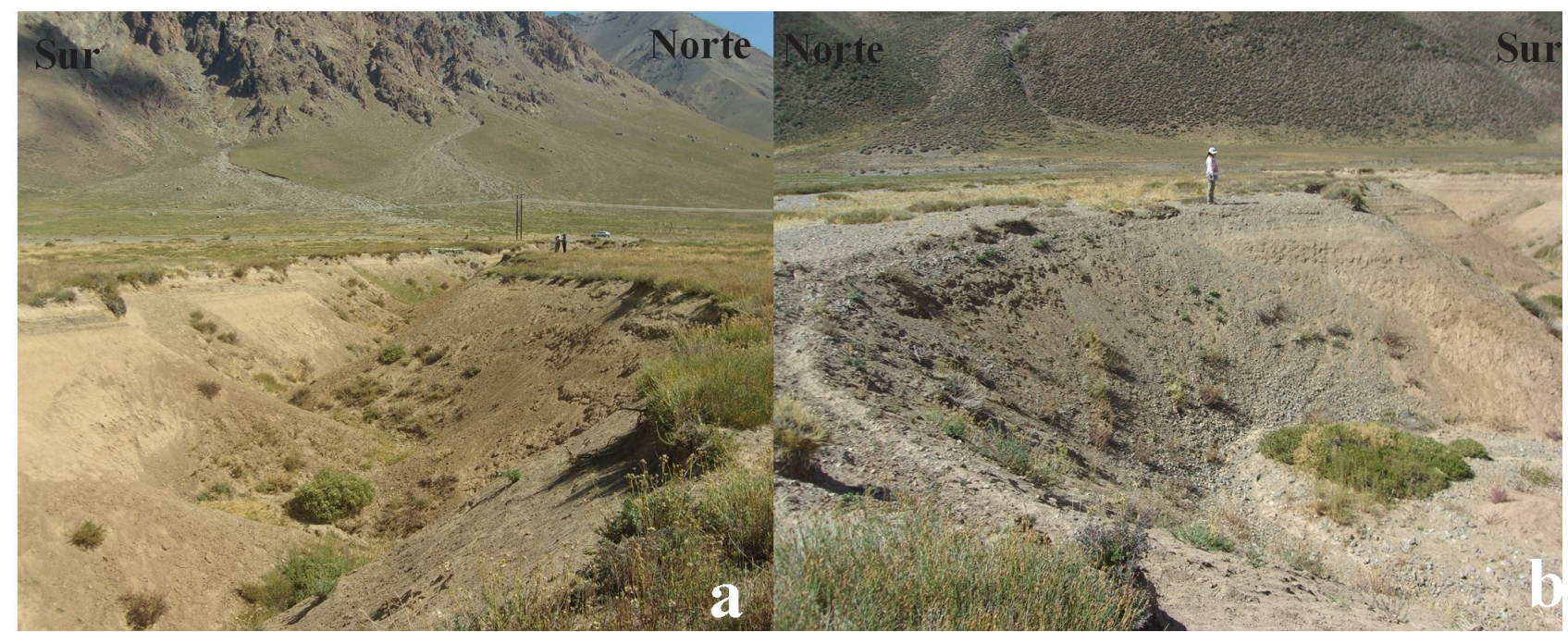

Figura 6. a) Vista frontal de Parada N. ${ }^{\circ}$, canyon karst. b) Acercamiento de una de las dolinas que lo conforman Fuente: fotografía elaboración propia. 


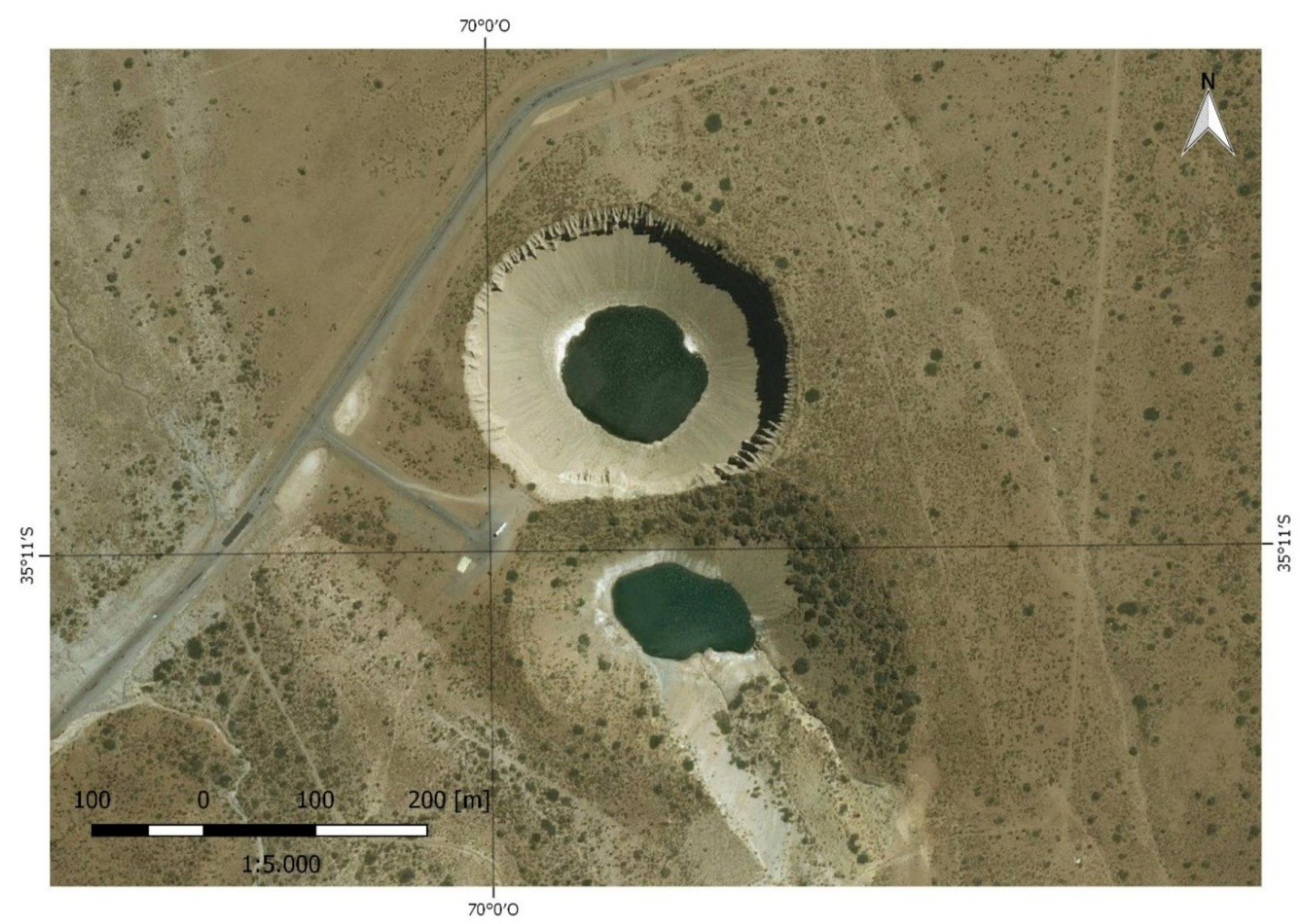

Figura 7. Pozo de Las Ánimas, en margen izquierdo Ruta Provincial 222. Geositio 2

Fuente: imagen satelital Bing, mapa elaboración propia.

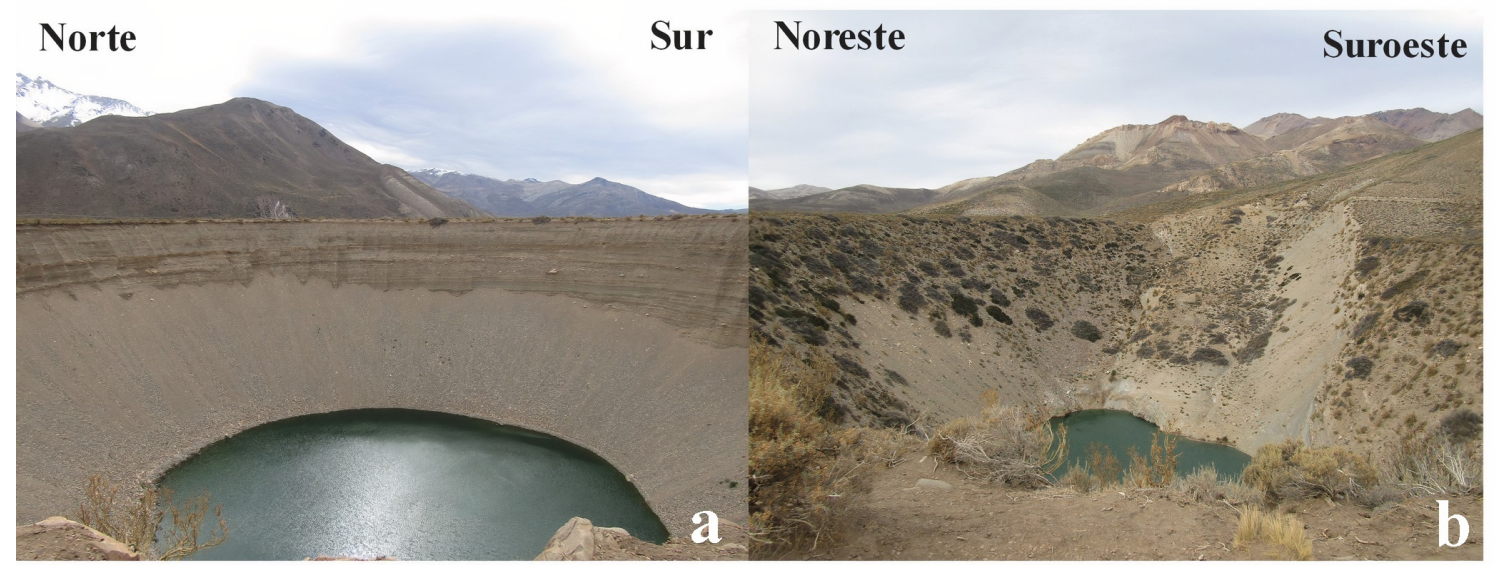

Figura 8. a) Vista frontal de dolina . $^{\circ}$ 2, pozo de Las Ánimas. b) Vista frontal de dolina N. ${ }^{\circ}$, pozo de Las Ánimas

Fuente: fotografías, elaboración propia. 


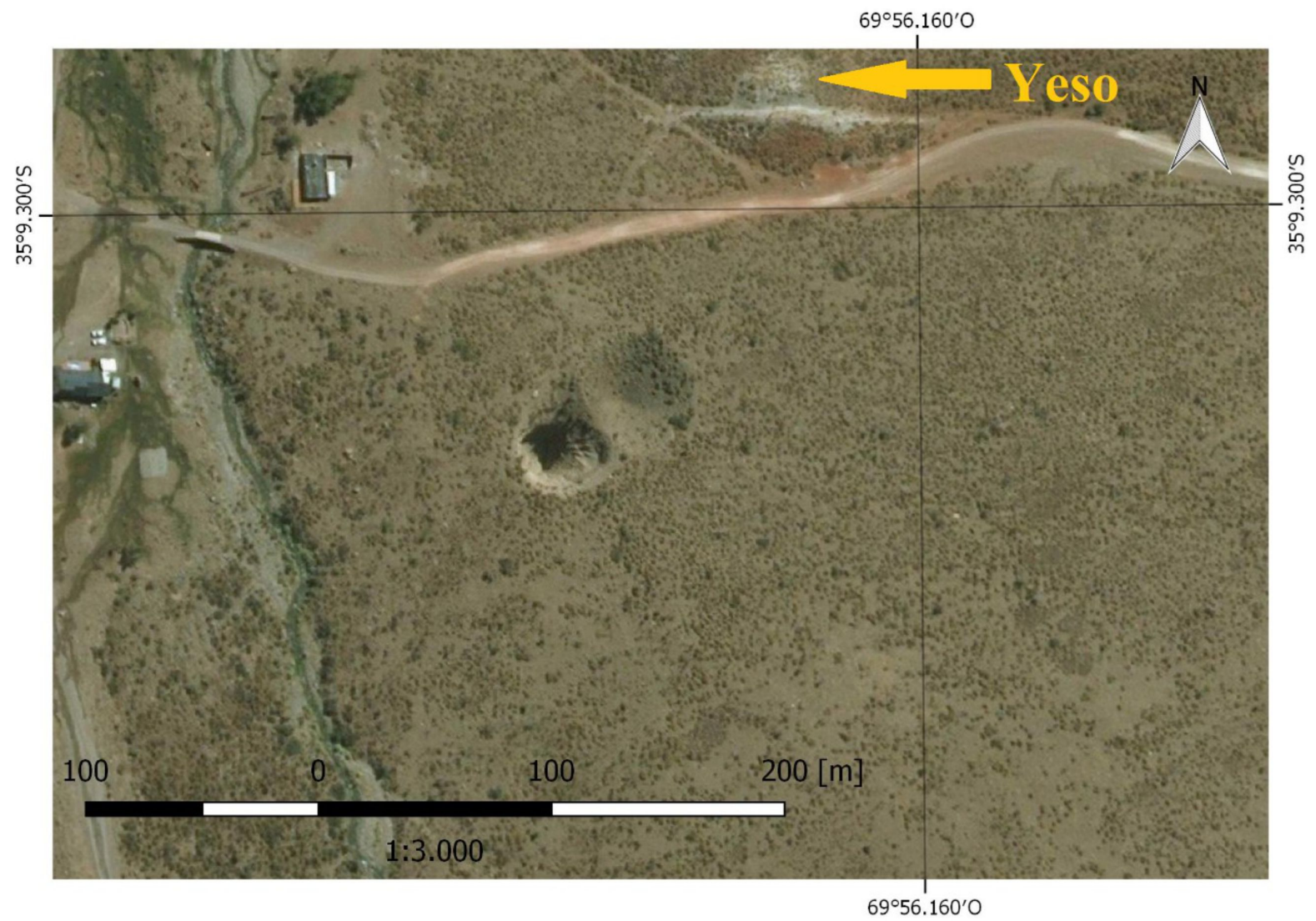

Figura 9. Dolinas del pozo de Las Animitas, en margen izquierdo Hostel Los Molles. Geositio 3

Fuente: imagen satelital Bing, mapa elaboración propia.

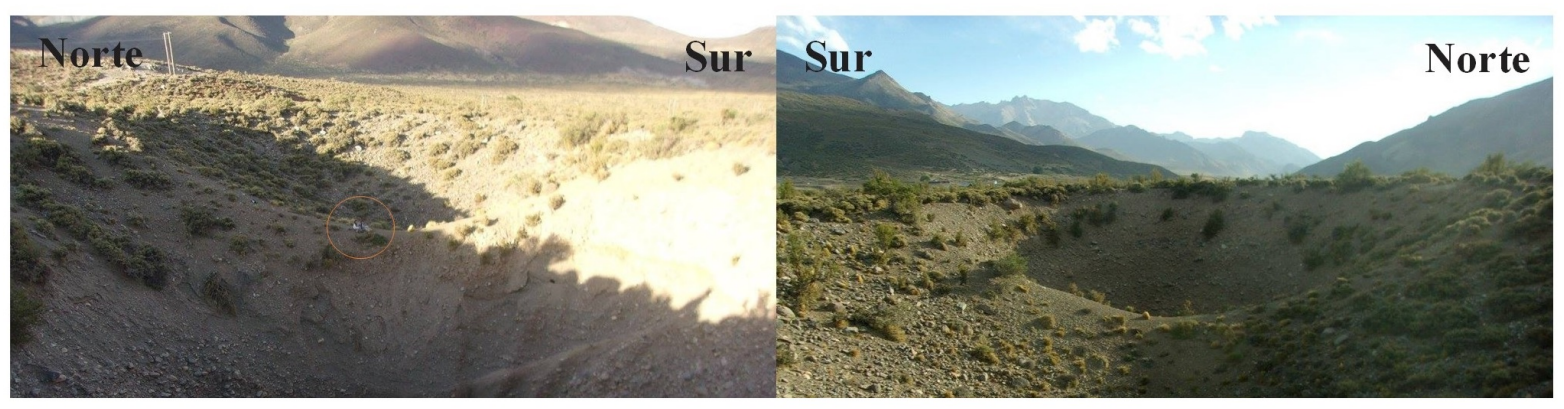

Figura 10. a) Vista este de dolinas N. ${ }^{\circ}$ y 5 . b) Vista oeste de dolinas N. 4 y 5, pozo de Las Animitas Fuente: elaboración propia.

Por último, la georruta finaliza también en Los Molles (figura 11), con la laguna de La Niña Encantada y la Lagunita (figura 13b). La dolina N. 6 fue la que obtuvo mayor puntuación total (casi perfecta); con valoraciones máximas en la mayoría de los criterios; de acuerdo con sus características 
que la identifican como única en toda la zona de estudio: en rareza posee valor máximo, al igual que en representatividad y parámetro estético máximo por su diversidad de colores y naturalidad del sitio (figuras 12a, 12b, 13a).

Sus valores adicionales también son máximos. Esta dolina en particular, con respecto a las demás, tiene importancia ecológica (valor ecológico); en ella hay un microclima que ha permitido el desarrollo de vida en su entorno tanto vegetal como animal, con peces en su interior y aves (figuras 13a, 13b, 13c, 13d, 14a, 13b). En cuanto a su importancia religiosa (valor cultural) se destaca por tener una gruta de la Virgen María; y en el aspecto histórico, al igual que el pozo de Las Ánimas, posee su propia historia local, la cual fue tomando distintas versiones al pasar los años; la más conocida es la leyenda de Elcha (en lengua aborigen significa espejo), que trata de la trágica vida de una hermosa princesa aborigen. Otra de las versiones involucra a sirenas que vivían en la laguna.

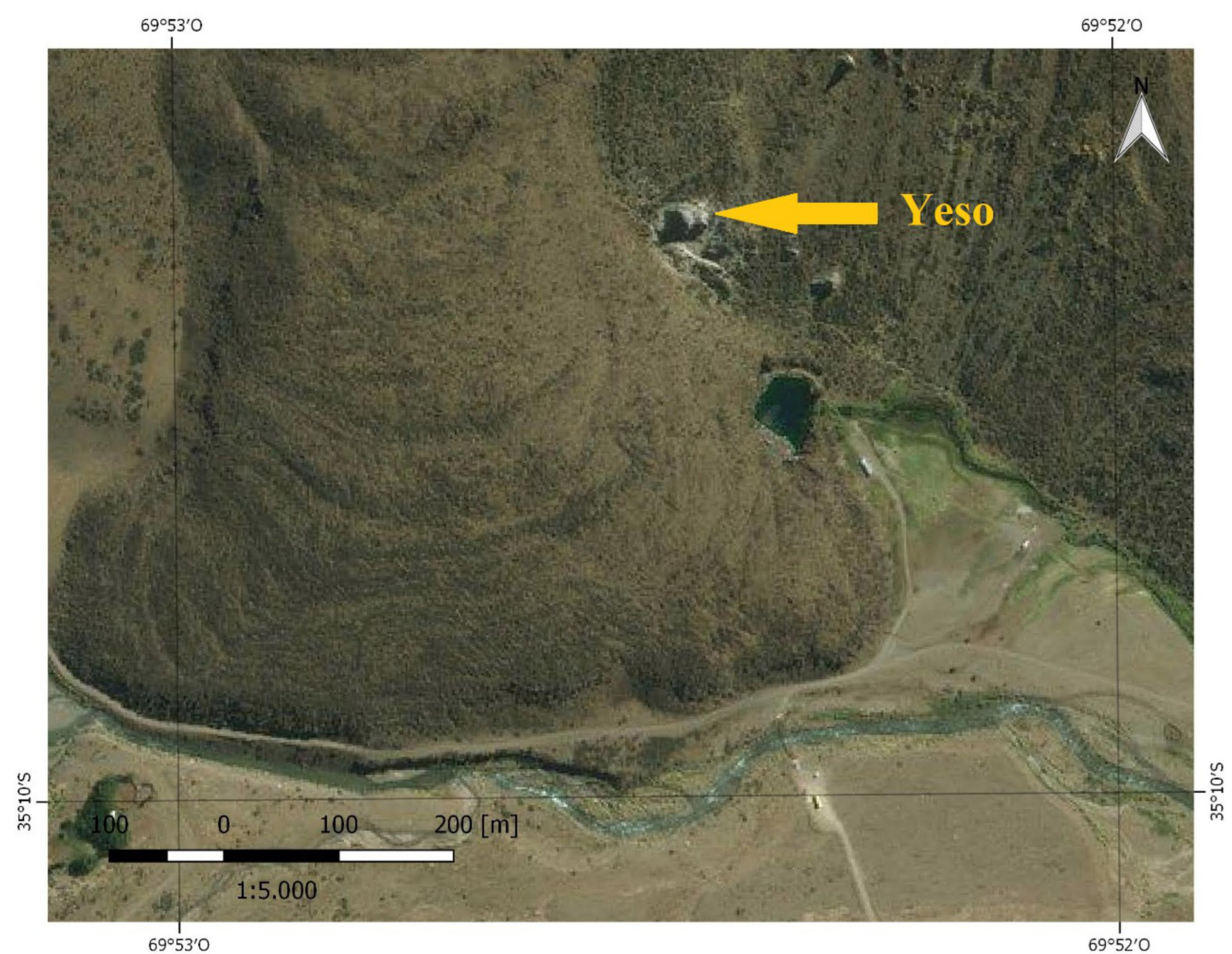

Figura 11. Dolinas Laguna y Lagunita de La Niña Encantada. En el centro de la imagen se puede ver una colada basáltica, y en el margen derecho, afloramientos de yeso. Geositio 4

Fuente: imagen satelital Bing, mapa elaboración propia. 


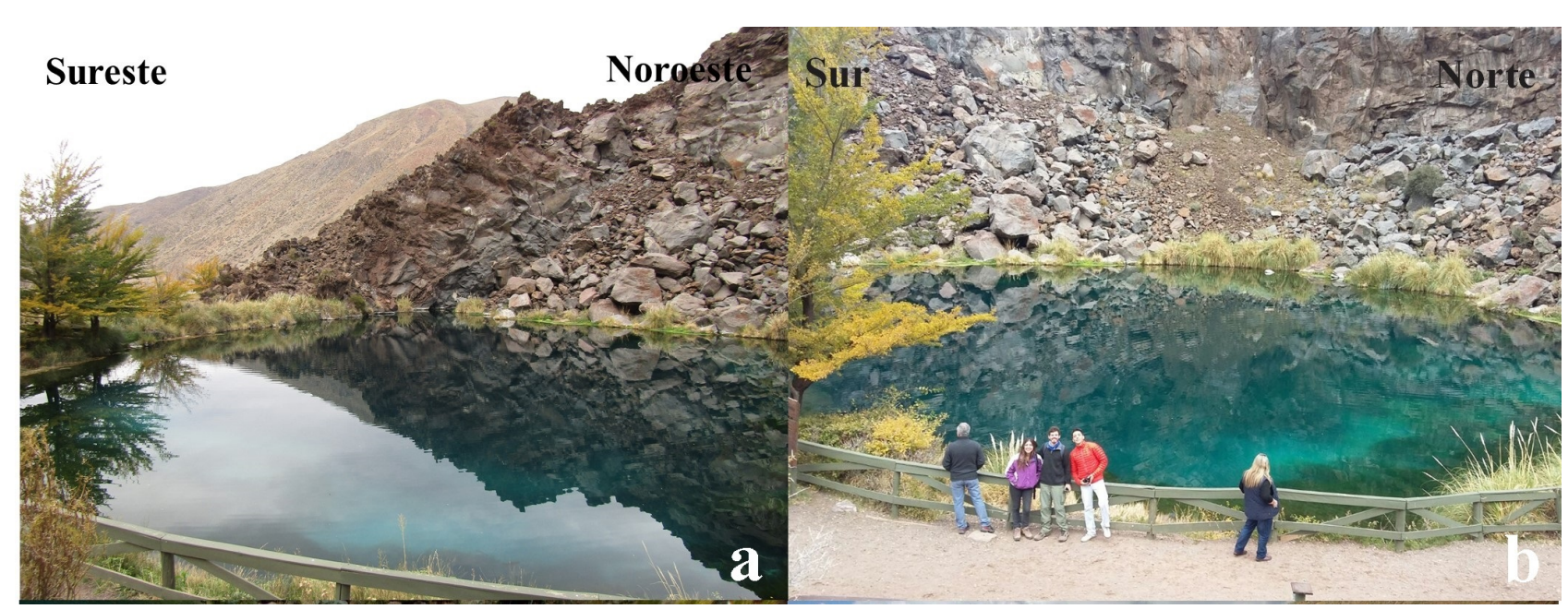

Figura 12. a) y b) Vistas lateral y frontal de dolina N. ${ }^{\circ} 6$ laguna de La Niña Encantada Fuente: fotografías, elaboración propia.

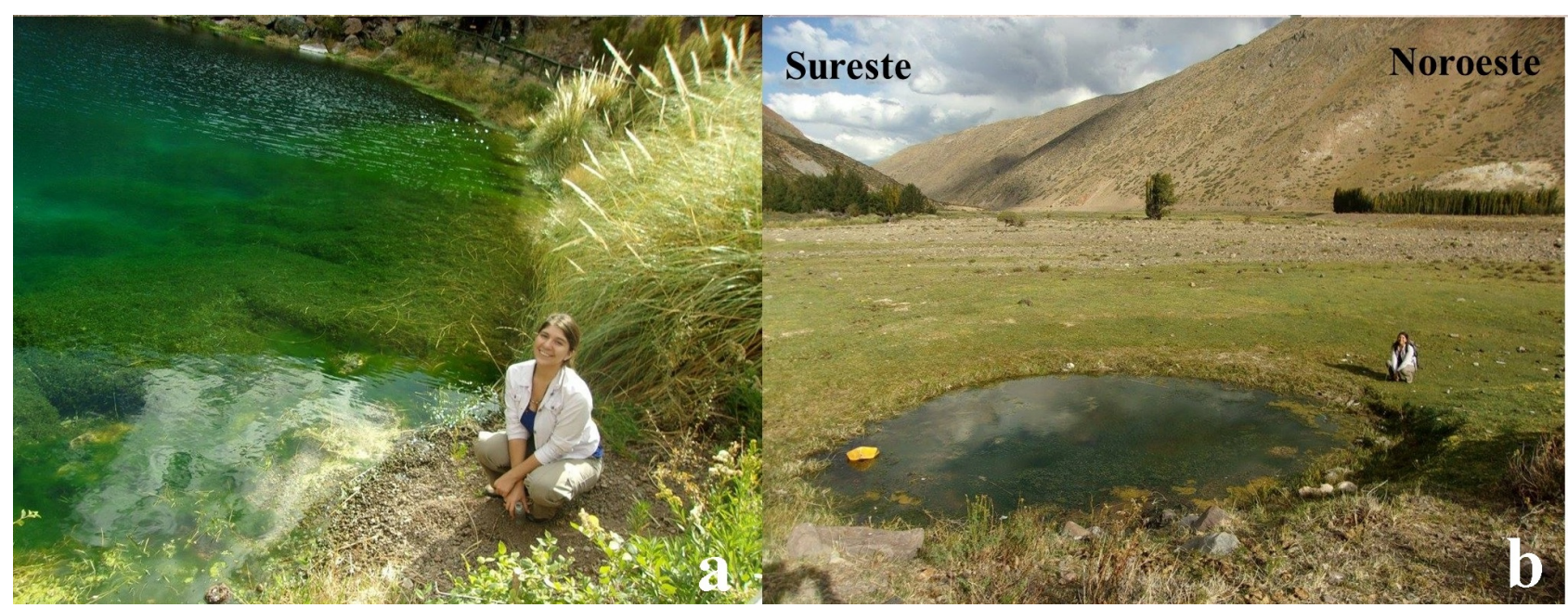

Figura 13. a) Acercamiento a dolina N. 6 donde se puede apreciar la coloración turquesa debida al yeso en su fondo y verde debido a la vegetación. b) Vista frontal de dolina N. ${ }^{\circ} 7$ lagunita de La Niña Encantada

Fuente: fotografías, elaboración propia.

Por último, se puntúa el valor de uso siendo su puntuación máxima, por constituir el sitio de interés geológico mejor dispuesto para los turistas, con buena accesibilidad, cartelería con información educativa y cultural, cuidado del ecosistema y medio ambiente a través de carteles y cestos de basura. Posee servicios como la atención de personal a la entrada del lugar, guía turístico, sanitarios, etc. 


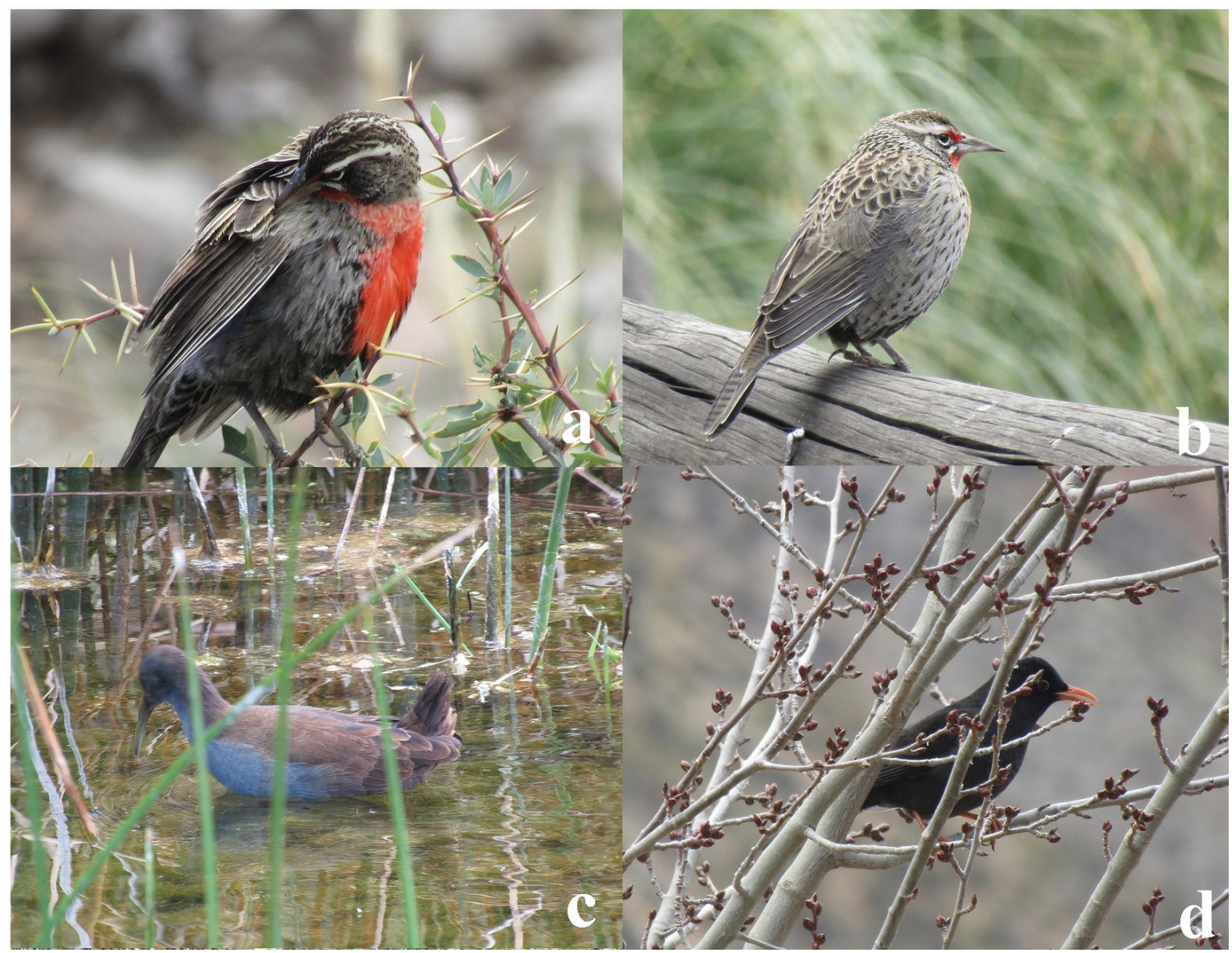

Figura 14. a) Aves observables en el geositio 4. Nombre científico: Leistes loyca. Nombre común: loica común. Individuo macho. b) Nombre científico: Leistes loyca. Nombre común: loica común. Individuo hembra. c) Nombre científico: Pardirallus sanguinolentus. Nombre común: gallineta común. d) Nombre científico: Turdus chiguanco. Nombre común: zorzal negro.

Fuente: elaboración propia.

\section{Georruta N. 2: zona sur (tabla II)}

De acuerdo con los geositios propuestos en esta georruta, se valoró a estas dolinas aisladas con bajos valores. A diferencia de la georruta anterior, en esta no hay ningún sitio de interés geológico establecido por la Municipalidad de Malargüe; y es este uno de los principales motivos de la diferencia de valores de una georruta a otra.

Los Castillos de Pincheira, nombrados previamente, son un sitio de interés geológico de origen no kárstico, el cual desde la ciudad de Malargüe posee su propio camino. A través de este, se puede acceder a las 8 dolinas propuestas (geositios de 5 al 11). Si bien la zona es aún prístina, hay huellas en toda el área y es posible acceder a cada una de las dolinas sin dificultad. 


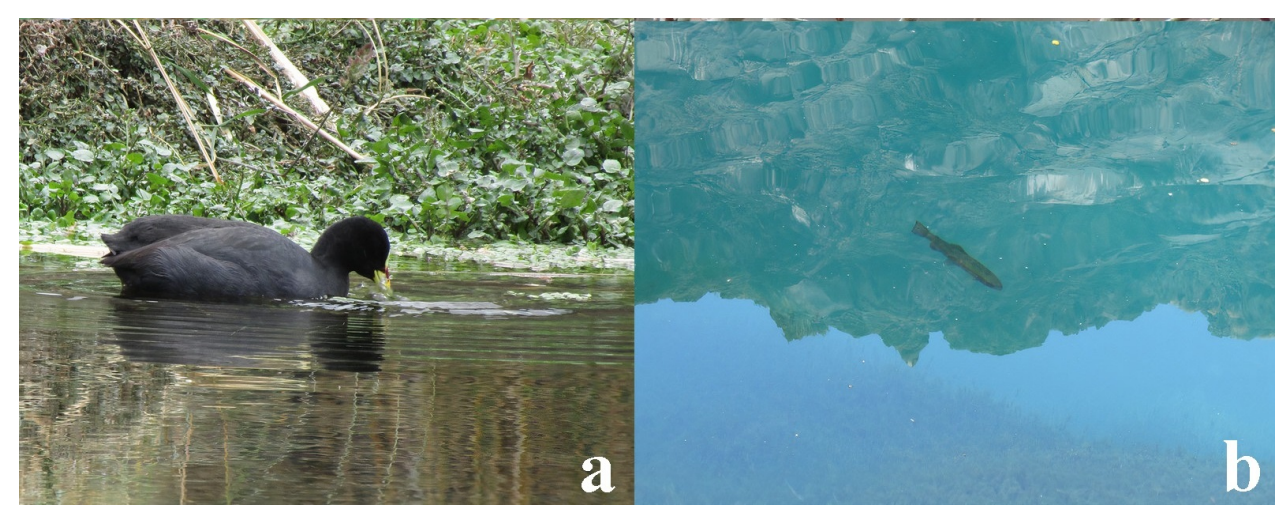

Figura 15. a) Fauna observable en el Geositio 4. Nombre científico: Fulica armillata. Nombre común: gallareta ligas rojas. b) Nombre científico: Oncorhynchus mykiss. Nombre común: trucha arcoíris

Fuente: elaboración propia.

De acuerdo con la rareza, en este caso se puntúa de forma media a las dolinas con agua (dolinas N. ${ }^{\circ} 8,14$ y 15) (figura 16, geositios 5 y 17, geositio 11), ya que la mayoría de ellas, en esta zona, no tienen agua en su interior. Asimismo, al contener agua poseen estéticamente diversidad de colores respecto a las demás. Los otros criterios fueron valorados con puntuación cero (0), por no poseer valor o por no disponer de más datos.

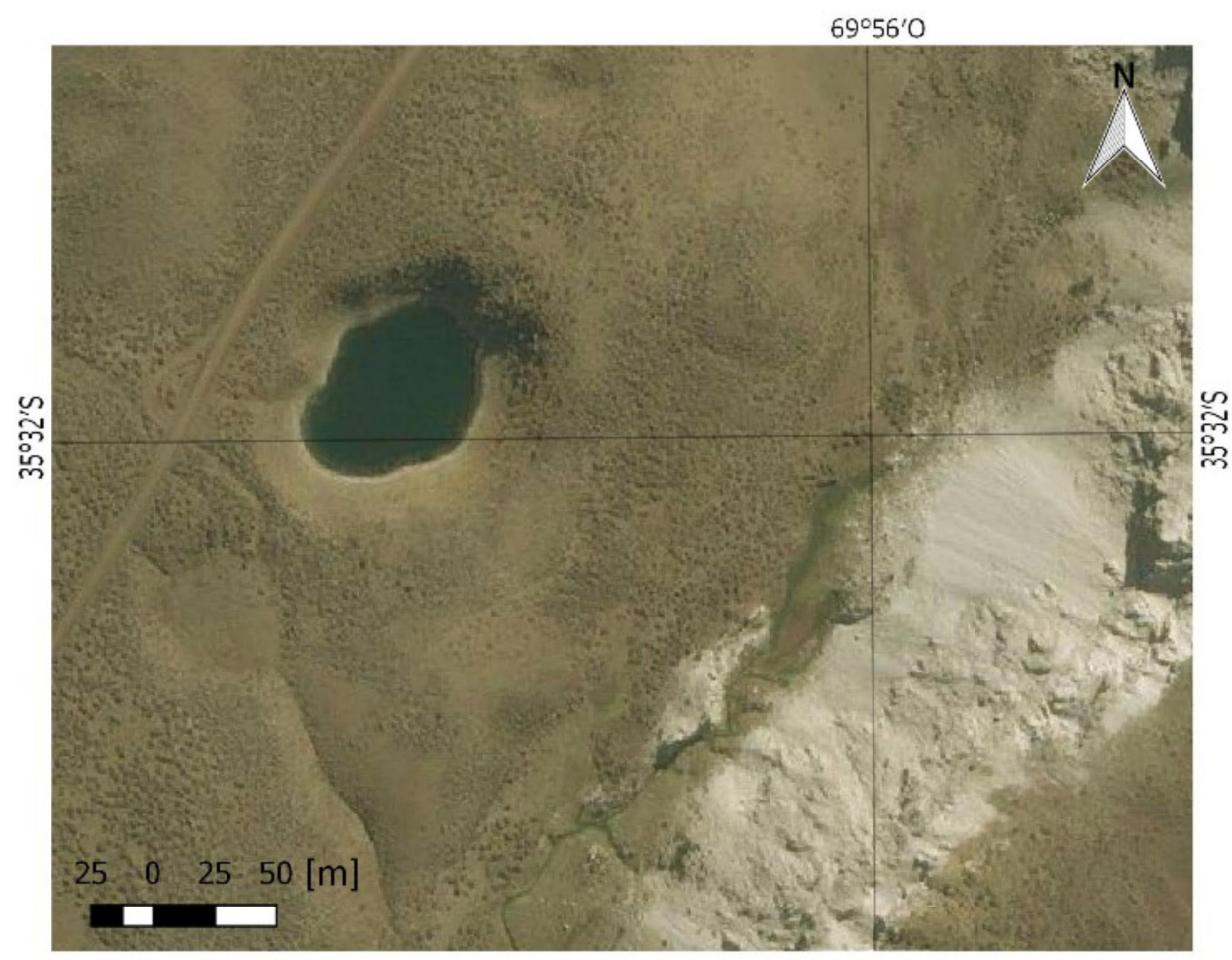

$69^{\circ} 56^{\prime} \mathrm{O}$

Figura 16. Dolina aislada N. ${ }^{\circ} 8$, en margen derecho se pueden observar afloramientos de yeso. Geositio 5 Fuente: imagen satelital Bing, mapa elaboración propia. 


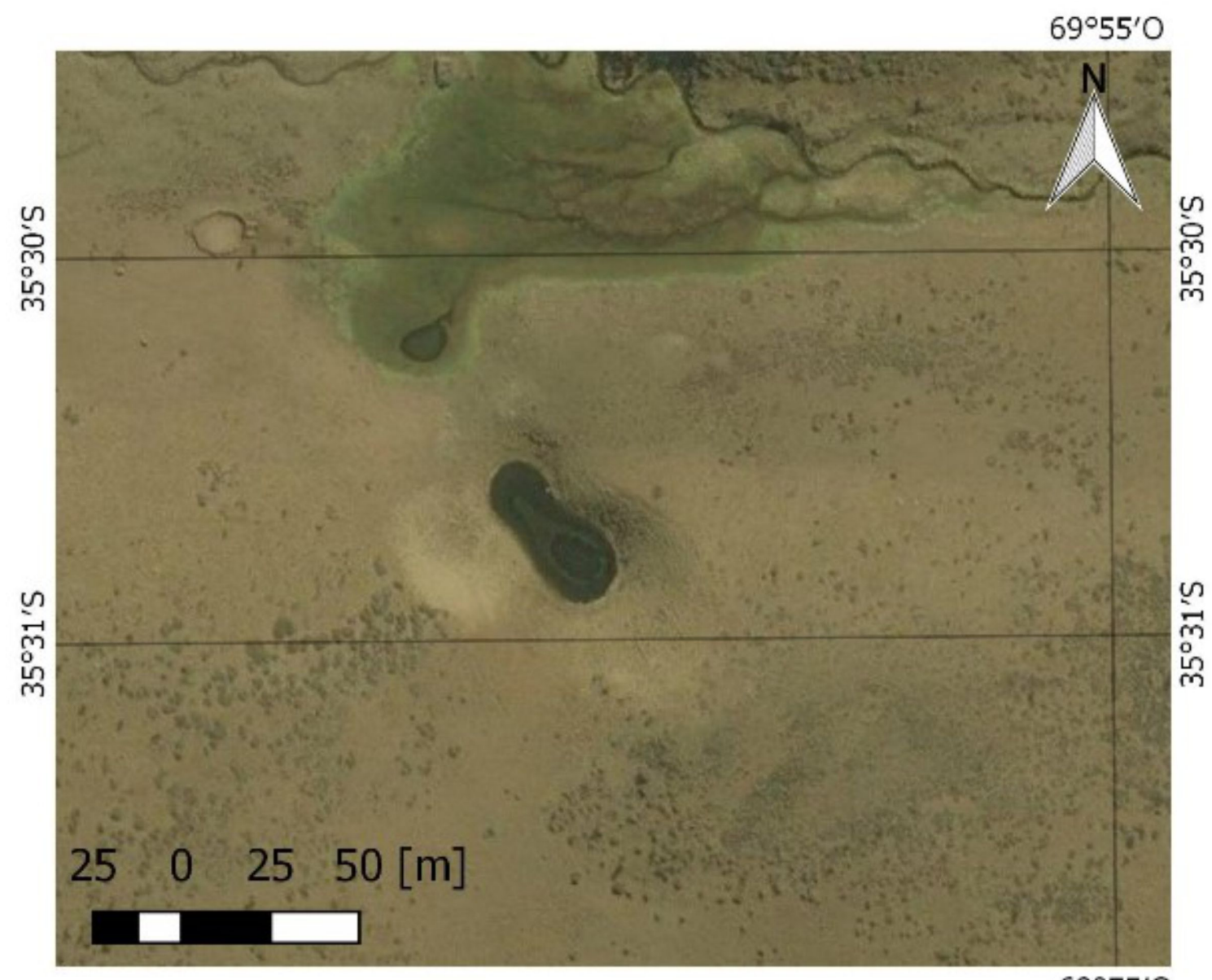

$69^{\circ} 55^{\prime} \mathrm{O}$

Figura 17. Dolinas aisladas (uvala) N. ${ }^{\circ} 14$ y 15 , se puede observar que inmediatamente en su extremo izquierdo se está formando una nueva dolina. Zona norte presencia de vegas. Geositio 11

Fuente: imagen satelital Bing, mapa elaboración propia.

\section{CONCLUSIONES Y RECOMENDACIONES}

Los datos obtenidos a partir de la valoración propuesta (valor científico, adicionales y de uso) sugiere que la primera georruta propuesta, ubicada al norte del área de estudio, comprendida por las dolinas $\mathrm{N}^{\circ} 1$ a N. ${ }^{\circ}$, es el más propicio para la determinación de geositios ante la Unión Internacional de Ciencias Geológicas (IUGS, por su sigla en inglés). La valoración más alta de esta georruta fue de 9 puntos, laguna de La Niña Encantada (Geositio 4), registro casi perfecto en todos los criterios de clasificación.

En la georruta propuesta 2, ubicada al sur del área de estudio, comprendida por las dolinas $\mathrm{N}$. $^{\circ}$ 8 a N. ${ }^{\circ} 15$, no hay ningún sitio de interés geológico establecido por la Municipalidad de Malargüe; 


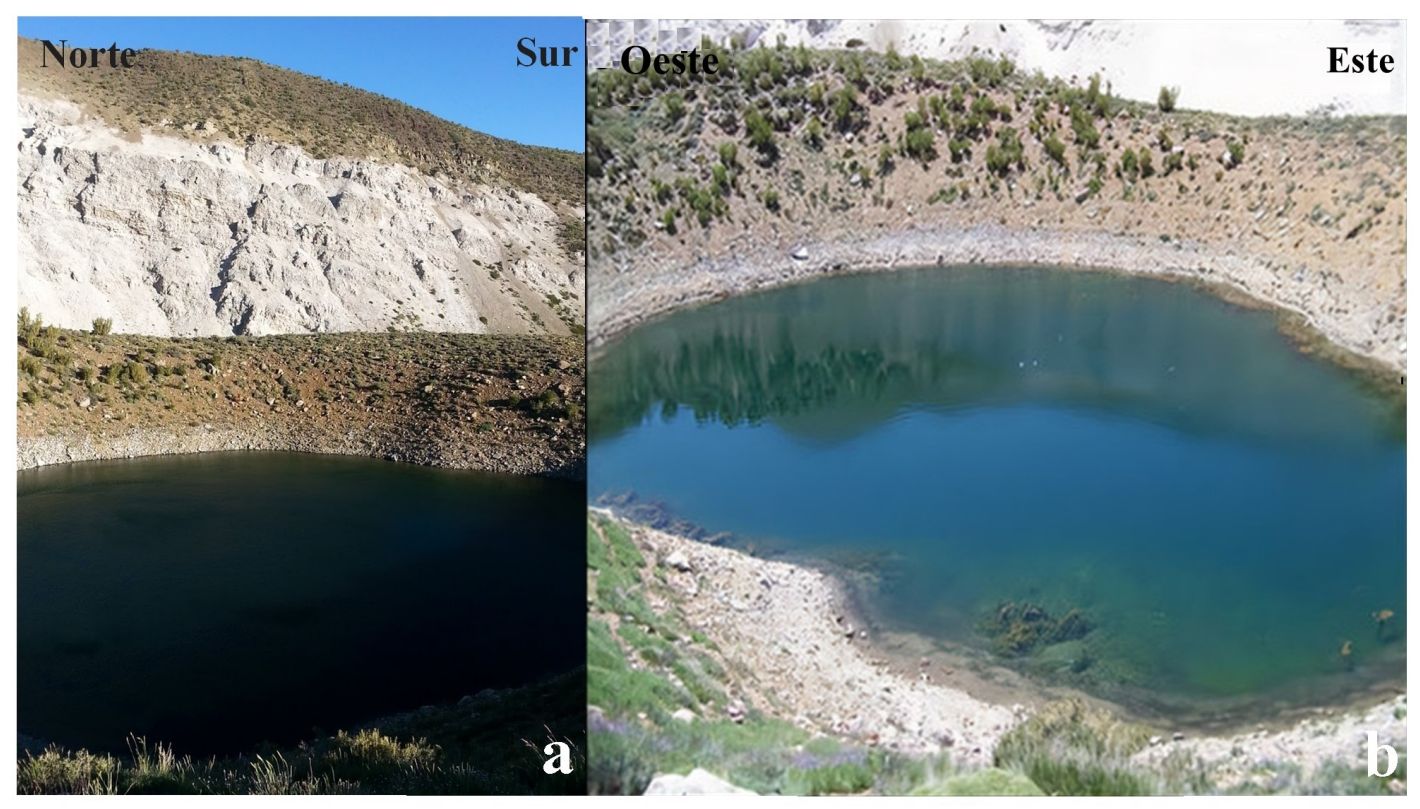

Figura 18. a) Vista frontal de dolina aislada N. 8 con afloramientos de yeso en sus inmediaciones. b) Vista frontal de dolinas aisladas (uvala) N. ${ }^{\circ} 14$ y 15.

Fuente: elaboración propia.

este es uno de los motivos por los cuales posee puntuación baja con respecto a la otra georruta. La puntuación máxima alcanzada en la misma fue de 3,2; comparado con la primera este resultado es muy bajo por lo que no sería propicio, hasta el momento, considerarlos como geositios.

Si bien este trabajo es básico en cuanto a valoración, se recomienda que estos sitios de interés geológico sean evaluados por especialistas de diferentes disciplinas (método Delphi), como: geólogos, biólogos, antropólogos, licenciados en turismo, etc. (Linstone y Turrof, 1975), con el fin de caracterizarlos en detalle y proponerlos de manera formal ante la IUGS. A su vez, se sugiere continuar con estudios de las geoformas exokársticas (dolinas, uvalas y canyon karst) ya que estos son muy escasos en el área de Malargüe. Los mismos serán de granutilidad ya que servirán para fomentar el turismo, la conservación y la difusión en el marco de un desarrollo sustentable para el departamento.

\section{FINANCIAMIENTO}

La institución que ayudó a financiar este informe fue el Departamento de Geología, perteneciente a la Facultad de Ciencias Exactas, Físicas y Naturales de la Universidad Nacional de San Juan, y ahorros personales. 


\section{REFERENCIAS}

[Cramer, 1941] Cramer, H. (1941). Die Systematic der Karstdolinen: Neues Jahrb. Mineral. Geol. Palaontol, 85, 293-382. $\uparrow$ Ver página 86

[Coratza et al., 2012] Coratza, P., Galve, J., Soldati, M. y Tonelli, T. (2012). Recognition and assessment of sinkholes asgeosites: lessons from the Island of Gozo (Malta). Quaestiones Geographicae, 31(1), 2535. https://doi.org/10.2478/v10117-012-0006-8 个Ver página 84, 85, 86, 88, 89, 93

[Cortez-Taillant, 2017] Cortez Taillant, V. (2017). Fenómenos kársticos asociados a dolinas en el departamento Malargüe, Mendoza: su interpretación para la gestión territorial. [Tesis inédita de licenciatura]. Universidad Nacional de San Juan, San Juan Argentina. $\uparrow$ Ver página

[Fassoulas, Mouriki, Dimitriou-Nikolakis y Iliopoulos, 2012] Fassoulas, C., Mouriki, D., DimitriouNikolakis, P. y Iliopoulos, G. (2012). Quantitative assessment of geotopes as an effective tool for geoheritage management. Geoheritage, 4, 177-193. DOI: 10.1007/s12371-011-0046-9. https: //doi.org/10.1007/s12371-011-0046-9 个Ver página 86

[Kiernan, 2010] Kiernan, K. (2010). Human impacts on geodiversity and associated natural values of Bedrock Hills in the Mekong Delta. Geoheritage, 2, 101-122. https://doi.org/10.1007/ s12371-010-0015-8 个Ver página 86

[Lewis, 2008] Lewis, I. D. (2008). Australia's Kanawinka Geopark - volcanoes and lakes, limestone and sinkholes. En Inaugural Global Geotourism Conference, 'Discover the Earth Beneath Our Feet' (pp. 251-256). 17-20 de agosto. Fremantle, Western Australia. $\uparrow$ Ver página 86

[Linstone y Turrof, 1975] Linstone, H. A. y Turrof, M. (1975). The Delphi method, techniques and applications. Boston: Addison-Wesley Publishing. $\uparrow$ Ver página 102

[Palacio-Prieto, De Castro-Martínez y González, 2019] Palacio-Prieto, J. L. P., De Castro-Martínez, G. F. y González, E. M. R. (2019). Geosenderos en el Geoparque Mundial Unesco Mixteca Alta, Oaxaca, México. Cuadernos Geográficos, 58(2), 111-125. https://doi . org/10 .30827/cuadgeo. v58i2. $7055 \uparrow$ Ver página 86

[Panizza, 1996] Panizza, M. (1996). Environmental geomorphology. Ámsterdam: Elsevier. $\uparrow$ Ver página 89

[Panizza y Piacente, 1993] Panizza, M. y Piacente, S. (1993). Geomorphological assets evaluation. Zeitschrift für Geomorphologie, N.F., 87, 13-18. ^Ver página 84, 85, 88, 89

[Pereira, Pereira y Caetano-Alves, 2007] Pereira, P., Pereira, D. y Caetano-Alves, M. I. (2007). Geomorphosite assessment in Montesinho Natural Park (Portugal). Geographica Helvetica, 62(3), 159168. https://doi.org/10.5194/gh-62-159-2007个Ver página 85,88 
[Pralong, 2005] Pralong, J. P. (2005). A method for assessing tourist potential and use of geomorphological sites. Géomorphologie: relief, processus, environment, 3, 189-196. https : / / doi . org/10. 4000 /geomorphologie. 350 个Ver página 89

[Regolini-Bissig, 2010] Regolini-Bissig, G. (2010). Mapping geoheritage for interpretative purpose: definition and interdisciplinary approach. En G. Regolini-Bissig y E. Reynard (eds.), Mapping geoheritage. Géovisions 35 (pp. 1-13). Lausana: Institut de géographie. $\uparrow$ Ver página 89

[Reynard, Fontana, Kozlik y Scapozza, 2007] Reynard, E., Fontana, G., Kozlik, L. y Scapozza, C. (2007). A method for assessing "scientific. ${ }^{a}$ nd ..$^{a}$ dditional values. ${ }^{\circ}$ geomorphosites. Geographica Helvetica, 62(3), 148-158. https://doi.org/10.5194/gh-62-148-2007 个Ver página 84, 88, 89

[Vdovets, Silantiev y Mozzherin, 2010] Vdovets, M., Silantiev, V. y Mozzherin, V. (2010). A National Geopark in the Republic of Tatarstan (Russia): a feasibility study. Geoheritage, 2, 25-37. https: //doi.org/10.1007/s12371-010-0010-0个Ver página

[Zouros, 2007] Zouros, N. C. (2007). Geomorphosite assessment and management in protected areas of Greece. Case study of the Lesvos island - coastal geomorphosites. Geographica Helvetica, 62(3), 169-180. https://doi.org/10.5194/gh-62-169-2007 †er página 84, 85, 88

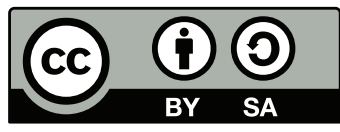

